\title{
Perception via the Deviated Eye in Strabismus
}

\author{
John R. Economides, ${ }^{1}$ Daniel L. Adams, ${ }^{1,2}$ and Jonathan C. Horton ${ }^{1}$ \\ ${ }^{1}$ Beckman Vision Center, Program in Neuroscience, University of California, San Francisco, San Francisco, California 94143, and ${ }^{2}$ Center for Mind/Brain \\ Sciences (CIMeC), The University of Trento, I-38122 Trento, Italy
}

\begin{abstract}
Misalignment of the eyes can lead to double vision and visual confusion. However, these sensations are rare when strabismus is acquired early in life, because the extra image is suppressed. To explore the mechanism of perceptual suppression in strabismus, the visual fields were mapped binocularly in 14 human subjects with exotropia. Subjects wore red/blue filter glasses to permit dichoptic stimulation while fixating a central target on a tangent screen. A purple stimulus was flashed at a peripheral location; its reported color ("red" or "blue") revealed which eye's image was perceived at that locus. The maps showed a vertical border between the center of gaze for each eye, splitting the visual field into two separate regions. In each region, perception was mediated by only one eye, with suppression of the other eye. Unexpectedly, stimuli falling on the fovea of the deviated eye were seen in all subjects. However, they were perceived in a location shifted by the angle of ocular deviation. This plasticity in the coding of visual direction allows accurate localization of objects everywhere in the visual scene, despite the presence of strabismus.
\end{abstract}

\section{Introduction}

Each retina contains a specialized region called the fovea, capable of highest acuity, which corresponds to the center of gaze. Soon after birth, infants align their eyes so that a single target is projected accurately onto both foveas. Fusion of the image from each eye provides a single view of the visual scene and permits stereopsis (Fox et al., 1980). In 2\% of children, this process fails, giving rise to strabismus (Donahue, 2007; Friedman et al., 2009; Pathai et al., 2010). Misalignment of the eyes results in diplopia because a target projected onto the fovea of one eye lands on peripheral retina in the other eye. It also causes visual confusion, from projection of different targets onto each fovea. Children with strabismus avoid these perceptual phenomena by suppressing images, giving rise to blind areas in the visual field known as scotomas. Unfortunately, suppression scotomas eliminate the error signal that would normally induce an adjustment in muscle tone to bring the eyes back into alignment.

Suppression scotomas are present only under binocular conditions; they disappear when one eye is occluded (von Graefe, 1854). Current descriptions of suppression scotomas in the visual fields of strabismic subjects are incomplete. In the deviated eye, it is thought that a local area of peripheral retina is suppressed to prevent diplopia and the fovea is suppressed to avoid visual confusion (von Noorden and Campos, 2002). However, if suppression were confined to only these two zones in the deviated eye, the

Received March 23, 2012; revised May 19, 2012; accepted June 7, 2012.

Author contributions: J.R.E., D.L.A., and J.C.H. designed research; J.R.E., D.L.A., and J.C.H. performed research; J.R.E., D.L.A., and J.C.H. analyzed data; J.R.E., D.L.A., and J.C.H. wrote the paper.

This work was supported by National Eye Institute Grants EY10217 (J.C.H.) and EY02162 (Beckman Vision Center), the Disney Award from Research to Prevent Blindness, and by the Larry L. Hillblom Foundation. Matthew K. Feusner and James V. Botelho assisted with computer programming. Technical support was provided by Cristina M. Jocson and Valerie L. Wu. We thank Charlene Hsu for referring subjects.

Correspondence should be addressed to Dr. Jonathan C. Horton, Beckman Vision Center, University of California, San Francisco, 10 Koret Way, San Francisco, CA 94143-0730. E-mail: hortonj@vision.ucsf.edu.

DOI:10.1523/JNEUROSCI.1435-12.2012

Copyright $\odot 2012$ the authors $\quad 0270-6474 / 12 / 3210286-10 \$ 15.00 / 0$ remaining retina would still give rise to diplopia and confusion because these sensations are not limited to the foveal regions.

Previous studies of suppression scotomas in human subjects were performed by testing perception in each eye under binocular conditions using various manual techniques (Travers, 1938; Jampolsky, 1955; Pratt-Johnson and Wee, 1969; Herzau, 1980; Sireteanu, 1982; Cooper and Record, 1986; Mehdorn, 1989; Melek et al., 1992; Joosse et al., 1999; Joose et al., 2000). Data from these early studies are difficult to interpret because ocular fixation was not monitored precisely and stimuli could not be delivered reproducibly. The development of automated, computerized perimetry has made it possible to analyze the visual fields more accurately because stimuli can be presented to either eye in random order and location, with strict control of duration, timing, and eye position (Johnson and Keltner, 1980). Using this approach, we have mapped suppression scotomas in subjects with strabismus and found that perception is active in the fovea of the deviated eye. To avoid visual confusion, a shift occurs in the perceived direction of the deviated fovea to cancel the eye's misalignment.

\section{Materials and Methods}

Participants. Twenty-nine subjects were enrolled in this study (age, 8-60; 13 males, 16 females). There were 18 subjects with childhood exotropia, 6 control subjects, and 5 subjects with adult-onset ocular misalignment. Subjects were referred by ophthalmologists at University of California, San Francisco (UCSF), or Kaiser Permanente, South San Francisco. Adults gave informed consent; minors gave assent and a parent provided informed consent. The study was approved by the UCSF Committee on Human Research and by the Kaiser Permanente Northern California Institutional Review Board. Subjects were paid \$20 to reimburse travel expenses.

Eligibility. All potential subjects received an ophthalmological examination to determine their eligibility for the study. The examination included assessment of best-corrected visual acuity in each eye, refractive error, pupils, color discrimination (Ishihara plates), eye movements, ocular alignment, and stereopsis (Randot circles and stereo butterfly). Slit 
lamp and dilated fundus examination were also performed. Criteria for inclusion in the study were as follows: (1) 20/20 Snellen visual acuity in each eye measured with optimal refractive correction, (2) exotropia since early childhood, (3) no eye disease except strabismus, (4) no history of amblyopia, (5) ability to alternate ocular fixation freely, (6) normal color vision, and (7) absence of diplopia. Subjects with $>4$ diopters of myopia, hyperopia, or astigmatism were excluded. Scotoma mapping was performed without refractive correction, unless subjects used contact lenses.

Goldmann visual field testing. In some subjects, the visual fields were tested using a Goldmann perimeter before mapping of suppression scotomas. They were seated with their head in a chin rest facing the interior of a white hemispheric bowl. A $1.5^{\circ}$ (size V isopter) diameter spot of light was moved slowly from the outer edge of the bowl toward the central fixation point. The subject signaled detection by pressing a buzzer. The visual field test was done first with the nonfixating eye patched, and then it was repeated with the nonfixating eye uncovered (see Fig. 1).

Visual field mapping of suppression scotomas. Subjects were seated in a dark room with their head supported in a chin/forehead rest facing a translucent tangent screen that subtended $\pm 50^{\circ}$ horizontally and vertically at a viewing distance of $57 \mathrm{~cm}$. Stimuli were rear-projected onto the screen using a calibrated digital light projector (Hewlett Packard model xb31; $60 \mathrm{~Hz}$ refresh rate) (Packer et al., 2001). It was controlled with a visual stimulus generator (VSG 2/5; Cambridge Research Systems) using custom software. The projected viewing area was $1024 \times 768$ pixels, with each square pixel $1.42 \mathrm{~mm}$ on a side. Eye movements were tracked using two infrared pan-tilt $60 \mathrm{~Hz}$ video cameras (iView X; SensoMotoric Instruments). The cameras were mounted overhead facing downward, using a hot mirror oriented at $45^{\circ}$ to image the subject's eyes without blocking the field of view. Infrared illumination was provided by an LED light source with a spectral peak at $940 \mathrm{~nm}$, which was invisible to subjects. Analog voltages representing the $X / Y$ position of each eye and the location of visual stimuli on the tangent screen were recorded digitally at $120 \mathrm{~Hz}$ for off-line analysis by a Power 1401 data acquisition and control system using Spike2 software (Cambridge Electronic Design).

Dichoptic stimulus presentation. Subjects wore specially constructed glasses containing dichroic filters, with red for the right eye and blue for the left eye. The frame fit closely to the face to prevent subjects from seeing around the lenses. The dichroic filters (Edmund Optics) matched the spectral transmission properties of the dichroic filters in the digital light projector color wheel. The blue filter was low pass with a cutoff at $501 \mathrm{~nm}$, and the red filter was high pass with a cutoff at $600 \mathrm{~nm}$. Measurements showed $0.092 \%$ transmission of red light through the blue filter and $0.28 \%$ transmission of blue light through the red filter. The problem of this "cross talk" was dealt with by showing stimuli against a textured background, consisting of a fine purple random dot noise pattern (each element, $0.14 \times 0.14^{\circ}$ ) visible to both eyes. A fresh background was generated on presentation of the fixation cross. The background pattern made it impossible for subjects to detect the faint second image that occurred from passage of the "wrong" color through the dichroic filter. It also helped subjects to stabilize their eyes at their customary ocular deviation during suppression scotoma mapping. When no background was used, subjects sometimes exhibited an exotropia that was larger or more variable than present during natural viewing. Stimuli were $0.5 \log$ units brighter than the purple background. At this brightness, stimuli were easy to detect throughout the visual field, unless they were suppressed.

Purple stimuli were intended to be perceived through the dichroic filters as isoluminant red and blue. Otherwise, a difference in the brightness of stimuli impinging on each eye might bias subjects' responses. In strabismic subjects, isoluminance could not be assessed through the filter glasses because interocular comparison was not possible. As an alternative, isoluminance was measured in six normal subjects. The mean red/ blue settings from these control subjects were used for the strabismic subjects. Isoluminance was determined using the minimum motion test (Anstis and Cavanagh, 1983), modified for dichoptic stimulation (Shadlen and Carney, 1986). For this test, the subject viewed an array of nine counterphasing gratings. The gratings consisted of sine waves that alternated in color between purple/gray and red/blue at $20 \mathrm{~Hz}$, phaseadvancing with each color switch. The gratings were displayed in a row, ordered by ratio of red/blue luminance. They appeared to move either up or down, unless the red and blue were isoluminant. The subject's task was to pick the single panel that showed ambiguous motion. Isoluminance values ranged narrowly among the six normal subjects. Accordingly, the same settings were used for all strabismic subjects. To assess the impact of relative brightness, the suppression maps in two strabismic subjects were repeated, varying the red or the blue setting by $10 \%$. This change made no difference to the appearance of the suppression maps.

Suppression scotoma mapping task. For suppression scotoma mapping, the subject fixated a central cross subtending $1^{\circ}$. It was either red or blue, on a random basis, for each trial (see Fig. 2). After the cross was foveated for 500-2000 ms by the eye behind the corresponding color filter, a $1.0^{\circ}$ spot was presented in the periphery for $200 \mathrm{~ms}$. The subject's task was to name the color of the peripheral spot. The verbal response was entered manually into the Power 1401 system to allow real-time compilation of visual field results and audiorecorded for later verification and backup.

For purple stimulus trials, the color reported by the subject depended on which eye was locally suppressed. For example, if a purple stimulus fell in a right eye suppression scotoma, it was perceived only via the left eye, and reported as "blue." Four strabismic patients responded "both" (i.e., they saw a red and a blue spot simultaneously) on most purple trials, indicating weak or absent suppression, despite the fact that they did not report diplopia during normal viewing. These subjects were excluded from further analysis.

Test stimuli were presented pseudorandomly at $5^{\circ}$ intervals over a grid measuring $\pm 30^{\circ}$ horizontally and $\pm 15^{\circ}$ vertically until every point had been tested once. In patients with a large exotropia, testing was extended to $\pm 40^{\circ}$ horizontally. Red, blue, and no-stimulus "catch" trials were interleaved occasionally (collectively $\sim 25 \%$ of the trials). Strabismic subjects could not tell the difference between single color catch trials and purple trials while performing the test. Responses on the unambiguous red and blue trials provided an assessment of patient reliability. As an additional measure of reliability, the entire test was repeated multiple times in each subject to check for consistency in each "layer" of the map.

In some patients, extra test points ( $10 \%$ of trials) were scattered within a radius of $2.5^{\circ}$ of each fovea, to probe their perceptual state at higher spatial resolution. These extra test points were programmed at the beginning of the dichoptic visual field testing. The location was based on measurement of the subject's ocular deviation with prisms before visual field testing. Inaccuracy in this measurement explains why sometimes the extra test points were not centered on the deviated eye's fovea (see Fig. 3 ). This problem was corrected for later subjects by using on-line feedback about the ocular deviation to program the extra perifoveal test points.

For each eye, $\sim 125$ trials were required to test each point on the grid with a purple stimulus, and to allow for catch trials. Thus, to compile a visual perception map for both eyes required 250 trials. Subjects averaged $20 \mathrm{~min}$ to complete 250 trials. The map was repeated three to five times, depending on the subject.

The dichroic filters transmit infrared illumination. Thus, one could monitor continuously the position of each eye with the video eye trackers during suppression scotoma mapping and ensure accurate fixation of the central cross. If fixation was broken, the trial was discarded. Responses were sorted according to eye fixation and trial type (suppression or catch) to generate plots of the data. The fill color of each white circle denoted the subject's verbal identification of the stimulus color. To generate maps interpolating between test stimuli, the fixating eye's position was set at the origin for every trial. This canceled any small error in tracker measurement or actual fixation. For each trial, the position of the peripheral test stimulus was translated by the same amount. The sparse position data ( $x$ and $y$ value of each stimulus locus) coupled with the subject's response ( $z=-1$ for red; 0 for both; 1 for blue) were interpolated by ordinary Kriging using a generalized spherical semi-variogram model (Chiles and Delfiner, 1999). This model relates the difference between response values at given locations to their physical displacement. It provides a measure of uncertainty that can be used to weigh local averages among neighboring points. The Kriging interpolation uses those local averages to predict the value of unknown locations in a stationary field. The interpolated maps were smoothed with a Gaussian kernel $\left(\sigma=3^{\circ}\right)$. 


\section{Results}

Binocular perception was tested in subjects with a history since early childhood of exotropia, or outward deviation of the eyes. All had 20/20 visual acuity in each eye, could alternate ocular fixation freely, and denied diplopia. The simplest explanation for the absence of diplopia would be that perception was suppressed entirely in the deviated eye. To test this idea, the visual fields were examined manually using a Goldmann perimeter. The subjects' task was to detect the appearance of a small light spot moving from the periphery toward the center of a hemispheric bowl. Figure 1 compares the monocular and binocular visual fields in a 9-year-old girl (subject 1 ) with a $16^{\circ}$ exotropia since the age of 8 months. The monocular visual field of each eye extended nasally $55^{\circ}$ along the horizontal meridian. After the deviated eye was uncovered, targets were detected out to $90^{\circ}$ (the maximum coverage of the hemispheric bowl). All subjects $(n=5)$ who were tested with this instrument showed an expansion of the visual fields to a full horizontal range of at least $180^{\circ}$ under binocular conditions. The increased size of the binocular visual fields, compared with the monocular visual fields, indicated that the deviated eye was not suppressed completely, but rather, that images falling on its peripheral nasal retina were perceived while viewing with both eyes open.

To delineate perceiving versus suppressed retina in the deviated eye, the visual fields were tested under dichoptic conditions (Fig. 2). A $1^{\circ}$ purple spot composed of isoluminant blue and red was presented briefly at a peripheral location. The subject's task was to identify the color of the spot. If the right eye was suppressed locally in the visual field where the spot was presented, the subject responded "blue," and vice versa. Occasional red, blue, or blank "catch" trials were interleaved randomly to assess the subject's reliability on unambiguous trials.

Dichoptic visual field maps in subject 1 showed a vertical border between the center of gaze for each eye, splitting the visual field into regions where perception was mediated by either the right eye or the left eye (Fig. 3). In regions where one eye was perceptually dominant, the other eye was suppressed. The suppression scotomas were relatively stable on the retinas, shifting location on the tangent screen with switches in fixation. Notably, the fovea of the deviated eye was not suppressed.

On catch trials, subject 1 identified red or blue targets accurately, even at locations where they were not seen when purple stimuli were presented (Fig. 3). For example, when fixating with
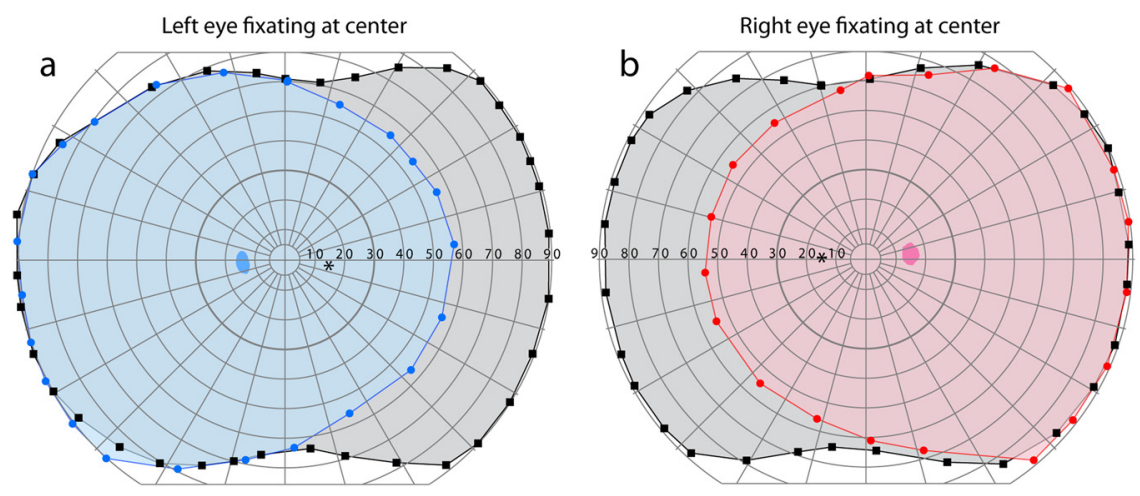

Figure 1. Perception via the deviated eye in subject 1. $\boldsymbol{a}$, Visual field of the left eye (circles, blue shading) plotted in a hemispheric perimeter, after patching the right eye. It extended from $90^{\circ}$ temporally to $55^{\circ}$ nasally. When the exotropic right eye was uncovered, the range of targets seen by the subject expanded horizontally to $180^{\circ}$ (squares). $\boldsymbol{b}$, Visual field of the right eye (circles, red shading), after patching the left eye. Opening the exotropic left eye increased the range of detected targets to $180^{\circ}$ (squares). With either eye fixating, uncovering the exotropic eye added $35^{\circ}$ (gray shading), indicating that targets landing on peripheral nasal retina of the deviated eye were perceived. The asterisk in each plot represents the approximate location of the deviated eye's fovea.

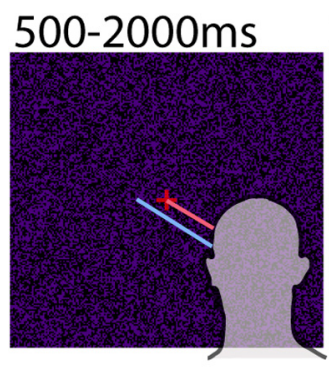

$200 \mathrm{~ms}$

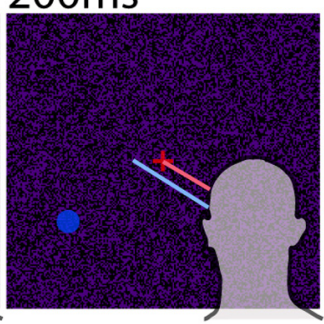

0-3000ms
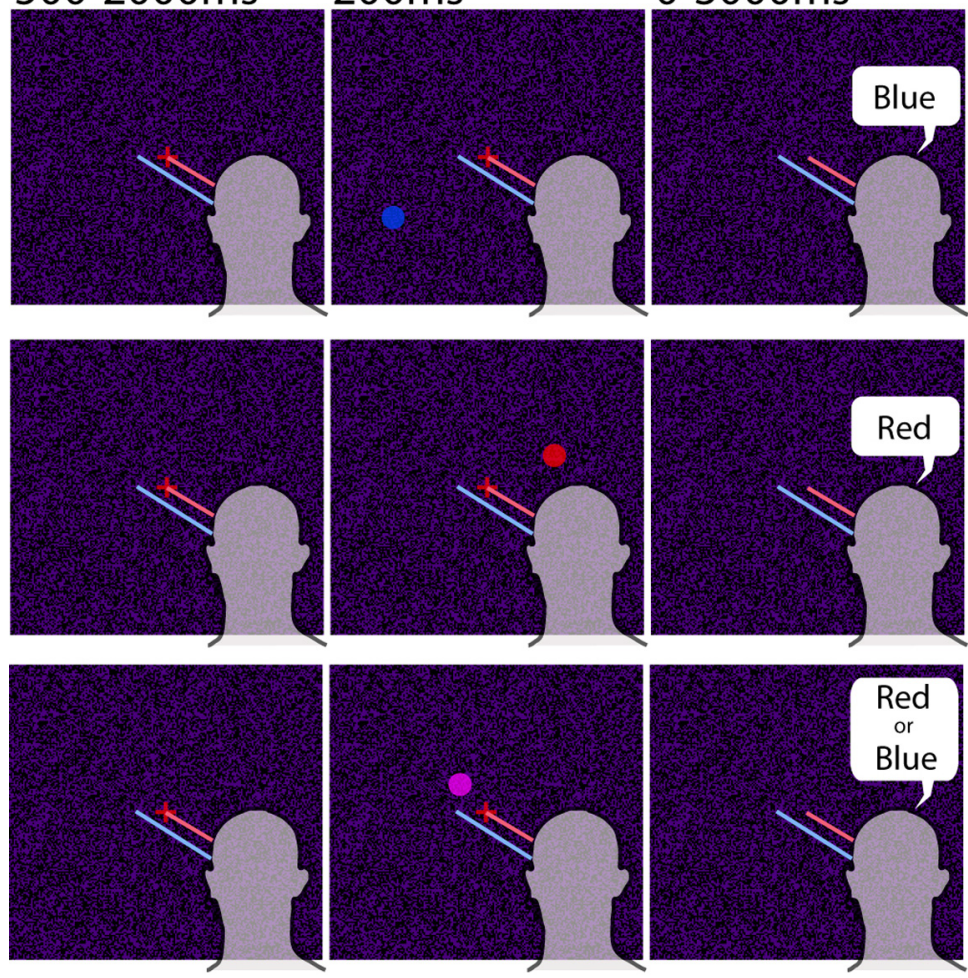

Figure 2. Dichoptic visual field testing for mapping of suppression scotomas in strabismic subjects. Each row shows an example of a different stimulus color: blue, red, and purple. Initially, the subject is sitting in the dark, wearing colored glasses (red for right eye; blue for left eye). The color of the fixation cross at the center of the tangent screen varies randomly between red or blue on individual trials. After the eye trackers detect fixation within an "on-target" window, a colored $1^{\circ}$ spot appears peripherally following a variable delay of $500-2000 \mathrm{~ms}$. The spot is presented for $200 \mathrm{~ms}$. The subject's task is to identify verbally its color. Fixation must be maintained on the central cross. The red and blue spots represent control trials; the purple spots composed of isoluminant red and blue provide information about visual suppression.

the right eye, a purple stimulus $20^{\circ}$ to the left of the vertical meridian was reported as blue because the temporal retina of the right eye was suppressed. However, a red stimulus shown at the same location was identified as red. This result indicates that only stimuli presented to both eyes simultaneously evoked suppression.

In this subject, exotropic deviation of the eyes occurred on an intermittent basis. When her eyes were aligned, she fused and had 
a
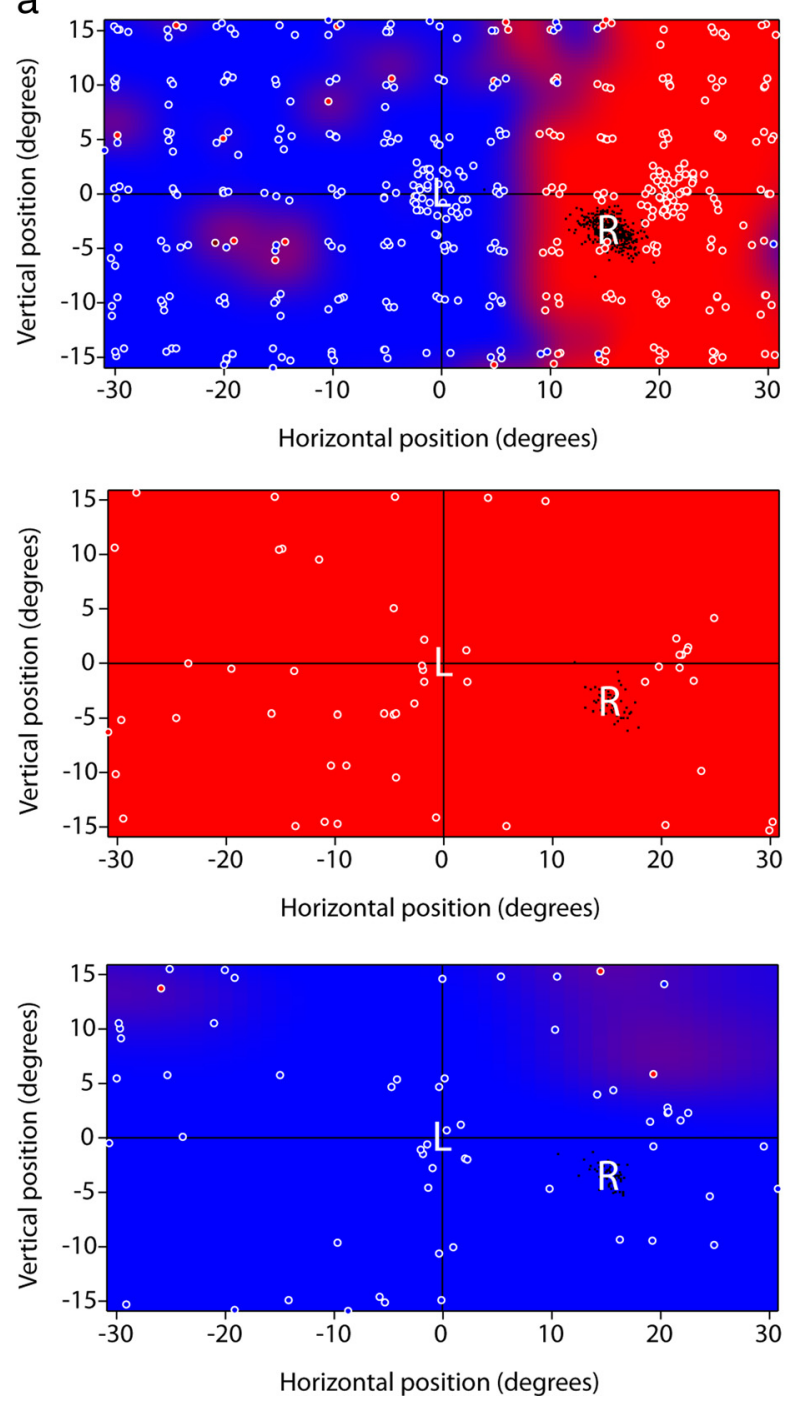

b
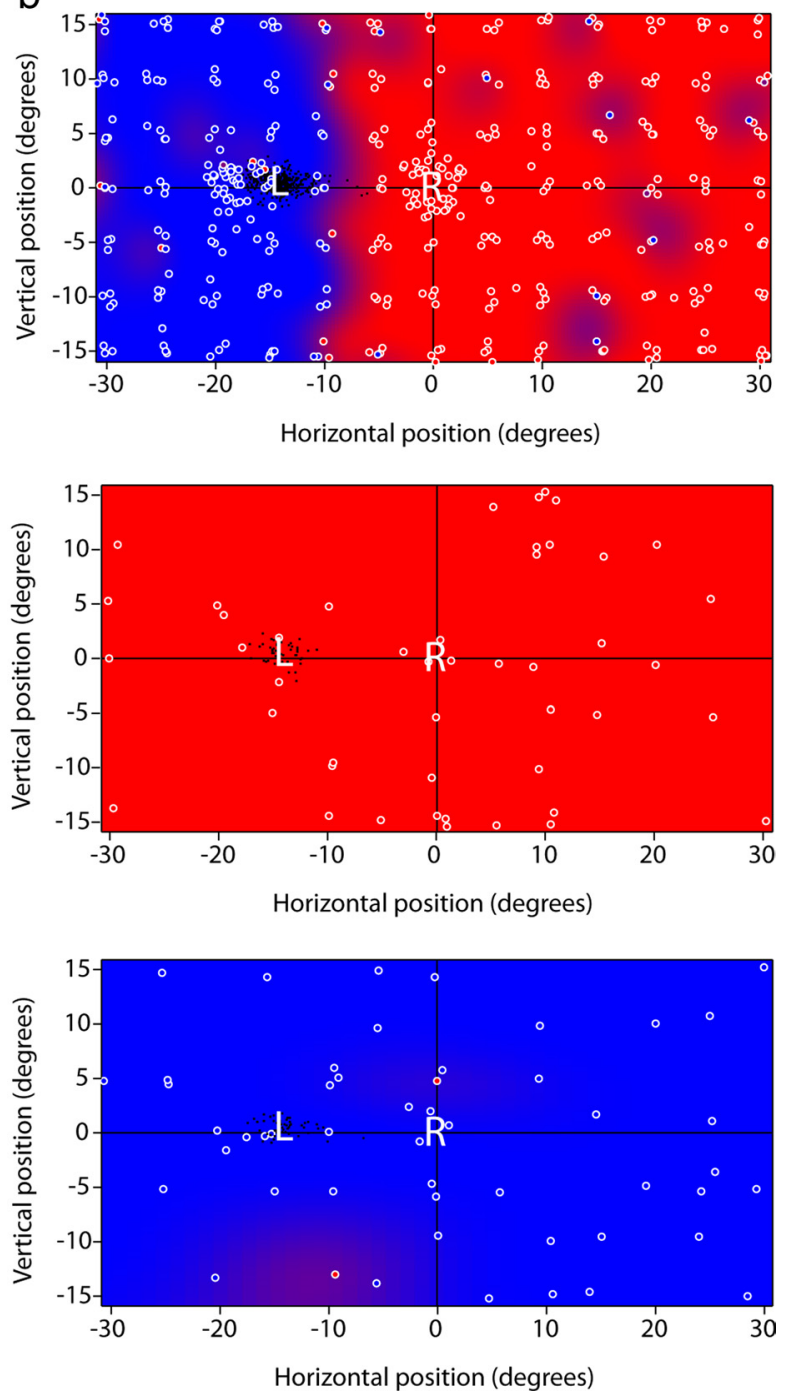

Figure 3. Suppression scotomas in subject 1. Visual field maps compiled from interleaved trials with either the left $(\boldsymbol{a})$ or right $(\boldsymbol{b})$ eye fixating on a cross at the center of the tangent screen. The center of gaze for the fixating eye has been set at the origin for all trials. The top row shows purple stimulus trials. Most points were tested four times; jitter in the location of each stimulus trial (white circles) reflects a correction corresponding to the difference in position between the fixation cross and the fixating eye, as measured by the eye tracker. The position of the deviated eye for each trial is plotted as a small black dot, forming a cluster underneath the letter for that eye. The fill color of the white circles indicates the subject's verbal response to a spot at that location: "blue," left eye perceiving; "red," right eye perceiving. The color shading is a smoothed Kriging interpolation of the data points. The middle row shows control trials with a red stimulus, with 99 of 99 correct responses. The bottom row shows control trials with a blue stimulus, with 106 of 111 correct responses. Forty-eight of 49 blank trials were correctly ignored.

normal stereopsis (40 arc-s). During dichoptic visual field mapping, the eye trackers detected occasional epochs of normal foveal alignment. These trials were analyzed separately (Fig. 4). They were characterized by scattered red or blue responses, forming an inconsistent map that differed markedly from the results obtained in the exotropic state. The map generated while the eyes were aligned resembled maps compiled from normal subjects $(n=6)$, who responded red or blue in an unpredictable fashion throughout the visual field. Their responses reflected the piecemeal, variable suppression that occurs from binocular rivalry.

When fusion was disrupted in normal subjects $(n=6)$ using prisms, a different sensation was experienced. On purple trials, subjects saw simultaneously a red and a blue spot, separated by the angular deviation caused by the prisms. Simultaneous detection of the red and blue components of the purple target occurred because there was no visual suppression. The same result was obtained in subjects $(n=5)$ with diplopia caused by ocular misalignment acquired in adulthood. Figure 5 shows the dichoptic visual fields in a man with diplopia for 1 year from a partial

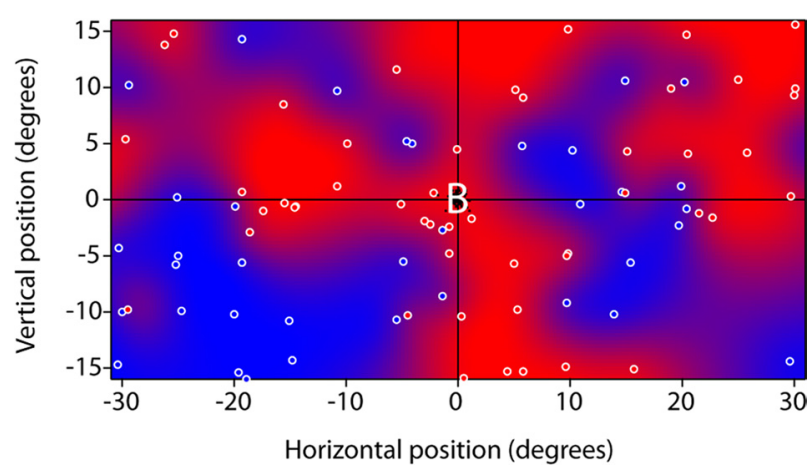

Figure 4. Responses during binocular fusion in subject 1. Plot of responses to purple stimuli (white circles) delivered while the eye trackers detected fixation of both (B) eyes at the origin. Responses of either "blue" or "red" were intermingled in a noisy pattern that bore little resemblance to the distribution of responses recorded during periods of exotropia (Fig. 3, top row). 
a
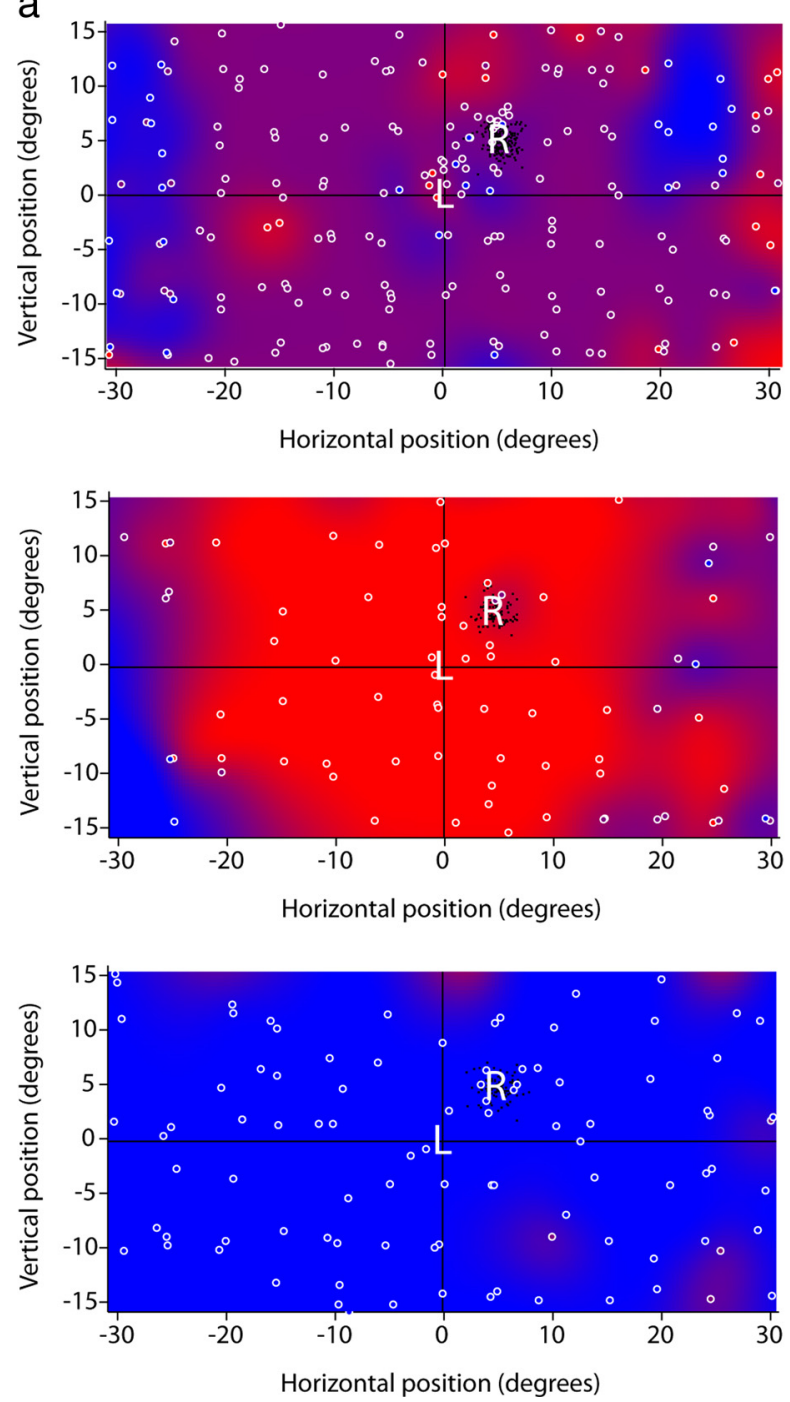

b
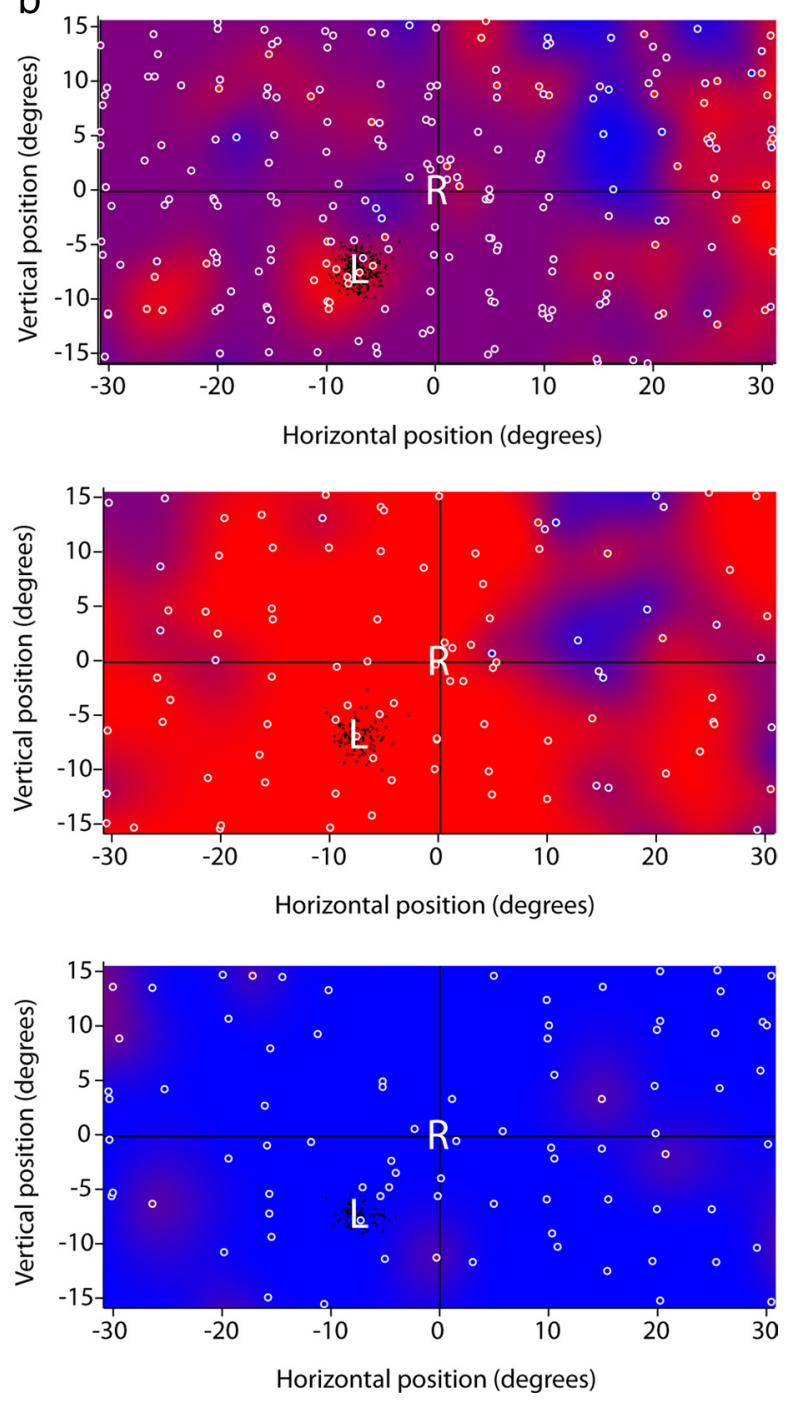

Figure 5. Dichoptic visual field testing in a 30-year-old man with exotropia from a traumatic partial oculomotor nerve palsy. Testing was conducted approximately a year after the onset of double vision. The plots show responses to trials with the left $(\boldsymbol{a})$ or right $(\boldsymbol{b})$ eye fixating at the center. Top row, Purple stimuli usually evoked a response of "both," depicted with a purple fill color because the subject lacked visual suppression. In contrast, exotropic patients with visual suppression had a different pattern of responses to purple stimuli (Fig. 3 top). Red (middle row) and blue (bottom row) stimulus trials were usually identified accurately, with either eye fixating.

oculomotor nerve palsy. Purple stimuli were perceived as separate red and blue spots on the majority of trials.

Dichoptic maps compiled from 12 additional subjects with childhood exotropia showed a consistent organization of suppression scotomas (Fig. 6). Each eye was dominant in its temporal visual field, regardless of which eye was fixating. In the nasal fields, the transition between perception and suppression occurred approximately midway between the center of gaze for each eye. In every subject, a suppression scotoma was present in both eyes, not just in the deviated eye. The suppression scotomas in each eye fit together in a complementary fashion to eliminate diplopia throughout the binocular visual fields (Fig. 7). The most striking finding was that the deviated eye's fovea was perceptually active in every subject.

With both foveas engaged simultaneously in perception, visual confusion might occur in a person with misaligned eyes because different images project onto each fovea. In addition, objects whose images fall on the deviated eye's fovea could be localized erroneously in space. Figure $8 a$ shows the results of dichoptic visual field testing in a 50-year-old woman (subject 2) with a right exotropia since age 2 . There was a characteristic pattern of suppression in each eye. An afterimage test was used to assess how she localized corresponding retinal points in space (Hillis and Banks, 2001). An electronic flash was used to illuminate the left retina with a horizontal bar of light, centered by a small gap on the fovea. In the same manner, a vertical bar was projected immediately afterward onto the right retina. The subject then drew the relative positions of the retinal afterimages. Looking straight ahead with the left eye, the foveal afterimage in the right eye was displaced horizontally to the right by $33^{\circ}$ (Fig. $8 a$ ). This separation was close to the magnitude of the exotropia, which averaged $29.2^{\circ}$. Her percept signified anomalous retinal correspondence, that is, a shift in the visual direction of images seen by the right eye relative to the left eye (von Noorden and Campos, 2002).

Afterimage testing was performed in five exotropic subjects; all showed anomalous retinal correspondence with a mean difference between afterimage separation and ocular deviation of only $2.5 \pm 1.9^{\circ}$. Control subjects with normal eye alignment $(n=$ 6) drew intersecting horizontal and vertical afterimages, cor- 

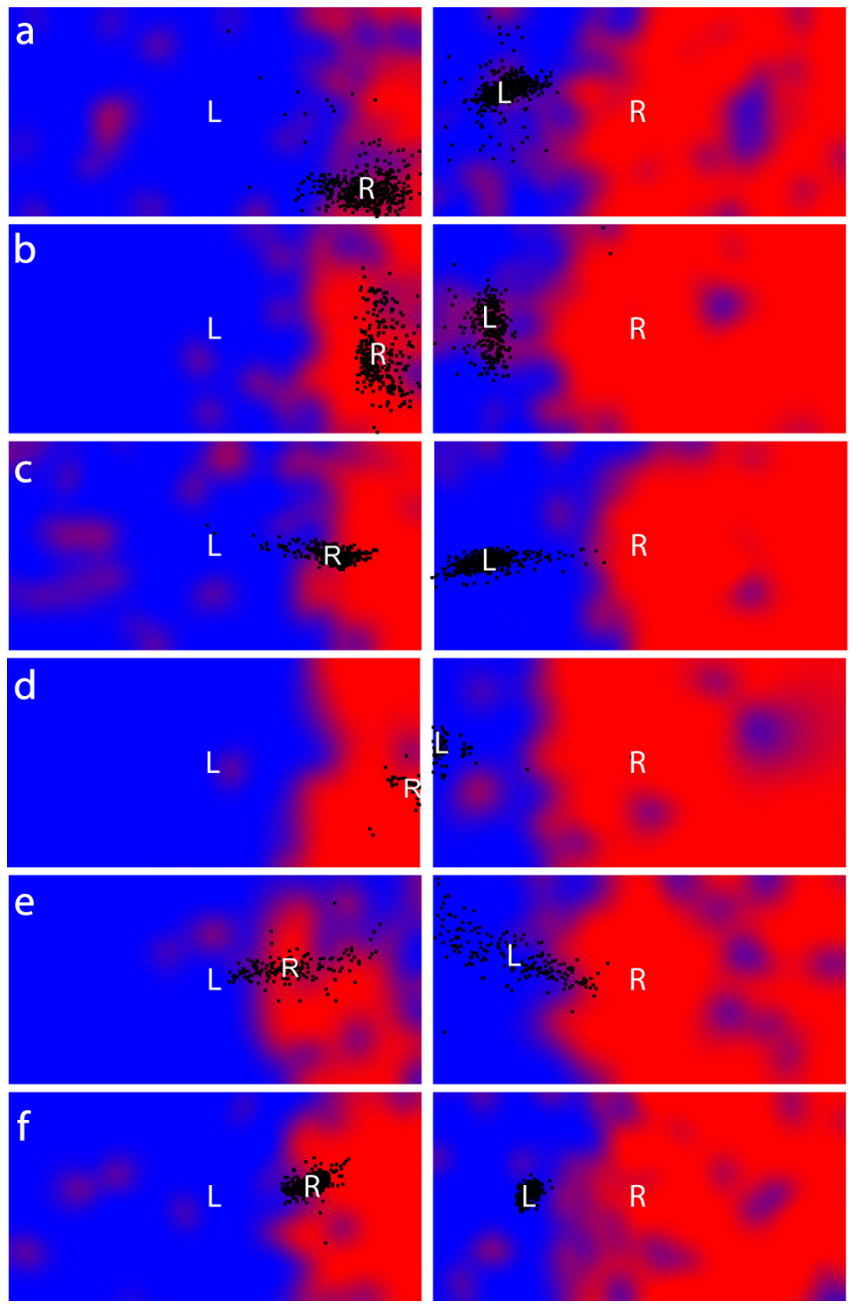
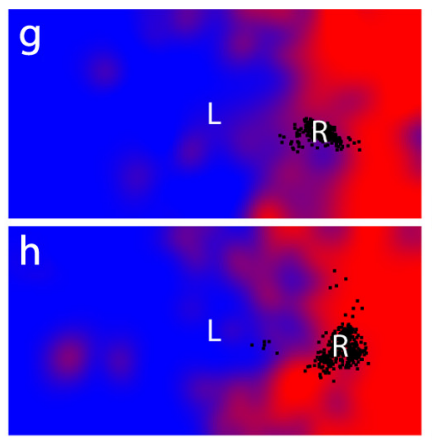
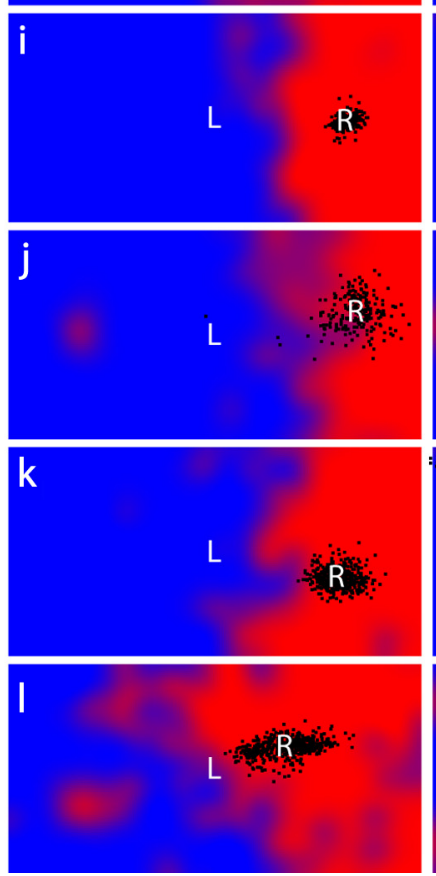

Figure 6. Dichoptic perimetry in 12 subjects $(\boldsymbol{a}-\boldsymbol{I})$ with exotropia. For each set of plots, the left panel shows responses with the left $(\mathrm{L})$ eye fixating and the right panel shows responses with the right (R) eye fixating. Fields subtend $60^{\circ}$ horizontally by $30^{\circ}$ vertically, with points tested approximately four times at every $5^{\circ}$ interval. The blue shading denotes regions where the subject responded "blue," signifying perception of a purple spot via the left eye alone. The red shading indicates regions where the subject responded "red" to the purple spot, corresponding to perception by the right eye alone. The black dots represent the position of the deviated eye on each trial. Subjects $\boldsymbol{c}$ and $\boldsymbol{e}$ had intermittent exotropia but did not fuse during testing.

responding to the location of the two foveas. The cross formed by the afterimages denoted normal retinal correspondence. Even if the eyes were deviated with prisms or displaced mechanically by pressure on the globe, normal subjects continued to perceive a cross.

All subjects showed variability in the size of their exotropia, as shown by scatter in the dots representing the position of the deviated eye during dichoptic visual field testing (Fig. 6). In subject 2, the exotropia ranged between 25 and $35^{\circ}$ on individual trials. Despite this variability in ocular deviation, she never reported seeing two targets-red and blue-on purple stimulus presentation. The absence of diplopia implies that the border between the suppression scotomas was labile, shifting over a range of $10^{\circ}$ as the ocular deviation changed from one moment to the next.

After suppression scotoma mapping, subject 2 underwent surgery on the horizontal rectus muscles to improve her eye alignment. The surgery resulted in an overcorrection of the exotropia. The subject noted constant diplopia immediately after the operation. Measurement with eye trackers revealed an esotropia that varied between 15 and $32^{\circ}$. Suppression scotoma mapping was repeated $4 \mathrm{~d}$ after surgery (Fig. $8 b$ ). The subject reported seeing red and blue targets simultaneously on most trials. After- image testing showed that, when she fixated centrally with the left fovea, the afterimage on the right fovea was still perceived on the right side. However, the fovea of the right eye now projected optically to the left side. The discrepancy between her perceived retinal correspondence and actual retinal alignment presumably accounted for her report of diplopia. At most locations, the purple spot now fell on portions of each eye's retina that were not suppressed.

Another surgical procedure was performed to correct the esotropic position of the eyes. The lateral rectus muscle was advanced, and its position was adjusted after the operation while the patient was awake to eliminate the esotropic deviation. Several weeks later, the subject reported that her double vision had improved. There was an exotropia measuring $5^{\circ}$. The subject could not fuse, even with prism correction, because of the early onset of her strabismus. Visual field testing revealed the same layout of suppression scotomas recorded before the initial surgery, but the foveas were separated by only $5^{\circ}$ (Fig. $8 \mathrm{c}$ ). The border where perception of the scene shifted from one eye to the other passed between the foveas. There was inconsistency in the identification of purple stimuli, especially centrally, reflecting the subject's report of occasional, persistent double vision. The afterimage test showed an anomalous retinal correspondence of $5^{\circ}$, equal to the 


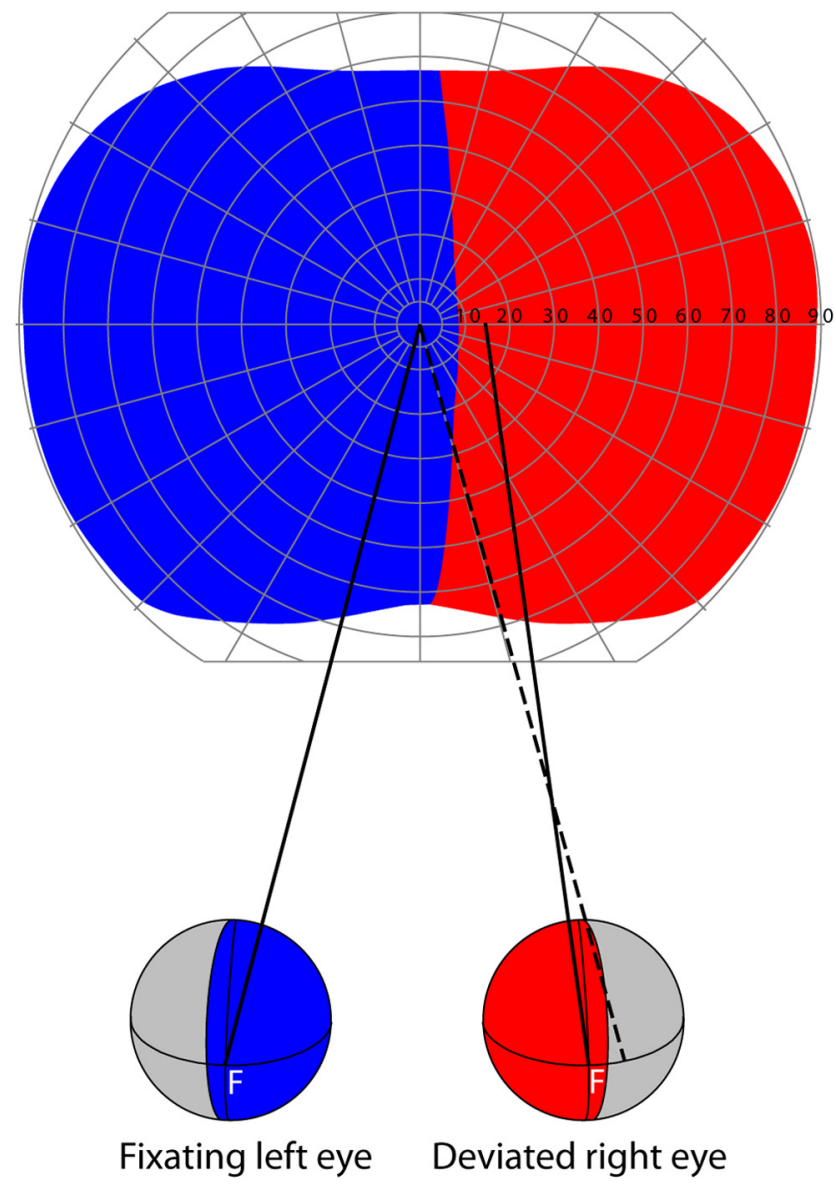

Figure 7. Schematic illustration of the portions of the visual field perceived with the left eye (blue) and right eye (red), while an exotropic subject fixates centrally with the left eye. There is suppression of part of the temporal retina (gray) in each eye, to avoid diplopia. Diplopia would arise if the temporal retinal locus in the deviating eye (dashed line) overlapping with the fovea in the fixating eye were perceptually active. The amount of temporal retina which is suppressed depends on the size of the ocular deviation: the smaller the deviation, the larger the region of suppression. If the subject switches to fixate centrally with the right eye, there is little change in the position of the border between perceiving and suppressed retina in each eye. F, fovea.

physical deviation of the foveas. Several months later, the patient reported complete resolution of double vision.

\section{Discussion}

People who acquire ocular misalignment as adults usually report diplopia and visual confusion. When strabismus appears early in life, these sensations are absent. The conventional explanation for this profound difference is that the developing visual system has sufficient plasticity to adapt by suppressing the deviated eye. Our data showed that this idea is only partly correct. With a bowl perimeter (Fig. 1), we demonstrated that the peripheral nasal retina in the deviated eye remains perceptually active in subjects with exotropia, even when the condition is acquired during childhood. In normal individuals, the visual fields of the eyes subtend together $\sim 200^{\circ}$. Exotropic individuals lack stereopsis, but they experience a more panoramic view of the world, because their total field of vision is expanded beyond $200^{\circ}$ by their ocular deviation.

For targets projected optically, the peripheral nasal retina in the deviated eye has no counterpart in the temporal retina of the fixating eye. With no retinal overlap, there is no potential for diplopia, and hence suppression is unnecessary. However, nasal retina closer to the fovea does overlap with temporal retina in the fixating eye, causing objects in the visual scene to fall on noncorresponding points in each eye. To explore how the visual system copes with this perceptual ambiguity, we mapped the visual fields dichoptically in exotropic subjects to probe which portions of the retina were suppressed during binocular viewing. The main finding was that there was suppression of the peripheral temporal retina in each eye (Fig. 7). Temporal suppression has been reported by previous investigators, using manual methods of field mapping in alternating exotropia (Jampolsky, 1955; Cooper and Feldman, 1979; Herzau, 1980, Melek et al., 1992). In the temporal retina, the transition from suppression to perception occurred approximately midway between the fovea and the point in the peripheral temporal retina corresponding to the fovea of the other eye. The larger the magnitude of the ocular deviation, the smaller the zone of suppressed temporal retina in each eye (Fig. 6). Suppression was not absolute: stimuli had to be presented to both eyes to evoke it.

Serrano-Pedraza et al. (2011) have reported suppression in intermittent exotropes like our subject 1 , when identical stimuli were flashed to the fovea of one eye and the temporal retina of the other eye, even under conditions of ocular fusion. This finding demonstrates that it is not ocular misalignment per se that generates suppression, but rather the conflict between identical stimuli landing on noncorresponding retinal points in each eye.

For stimuli of a given size, the ability to discriminate colors declines with increasing distance from the fovea (Mullen and Kingdom, 2002). The use of colored filters for dichoptic stimulation raises the possibility that subjects simply reported the color of the light spot falling closest to each fovea because it appeared more vivid. This trivial explanation for our findings can be ruled out by noting that the size $\left(1^{\circ}\right)$ and contrast $(0.5 \log$ units brighter than background) of the purple spot were sufficient for normal subjects to recognize the simultaneous appearance of both a red spot and a blue spot when their eyes were separated by a prism. In addition, adult subjects who had a freshly acquired exodeviation reported a red spot and a blue spot. Thus, both colored spots were detected readily in subjects without suppression, not just the spot nearest each fovea. In strabismic subjects, it would be worth varying the strength of the red/blue settings comprising the purple stimulus to determine the relative strength of suppression at each location in the visual field. However, a threshold mapping strategy requires many more trials. For this reason, we used fixed, suprathreshold luminance values for red and blue to delineate the basic pattern of visual suppression in each eye.

Hubel and Wiesel (1965) reported that, in animals raised with exotropia, $80 \%$ of cells in striate cortex respond to only one eye. Excitatory monocular inputs that normally converge onto binocular cells are induced to segregate by strabismus because the receptive fields in each eye are driven by incongruent stimuli (Tychsen et al., 2004). For many monocular cells, simultaneous stimulation of the other eye reduces their responsiveness, suggesting that inhibitory projections exist between populations of neurons favoring the right eye or the left eye (Freeman and Tsumoto, 1983; Sengpiel et al., 1995; Zhang et al., 2005). Interocular suppression in strabismic cats can be blocked by intracortical injection of bicuculline, a $\mathrm{GABA}_{\mathrm{A}}$ antagonist (Sengpiel et al., 2006). These data offer a potential mechanism for how one eye could turn off signals generated by stimulation of the other eye in strabismus. It is unclear, however, whether visual suppression occurs in the anesthetized state. Studies in alert, behaving strabismic animals would be valuable to correlate the discharges of single cells in striate cortex with patterns of suppression in the visual 

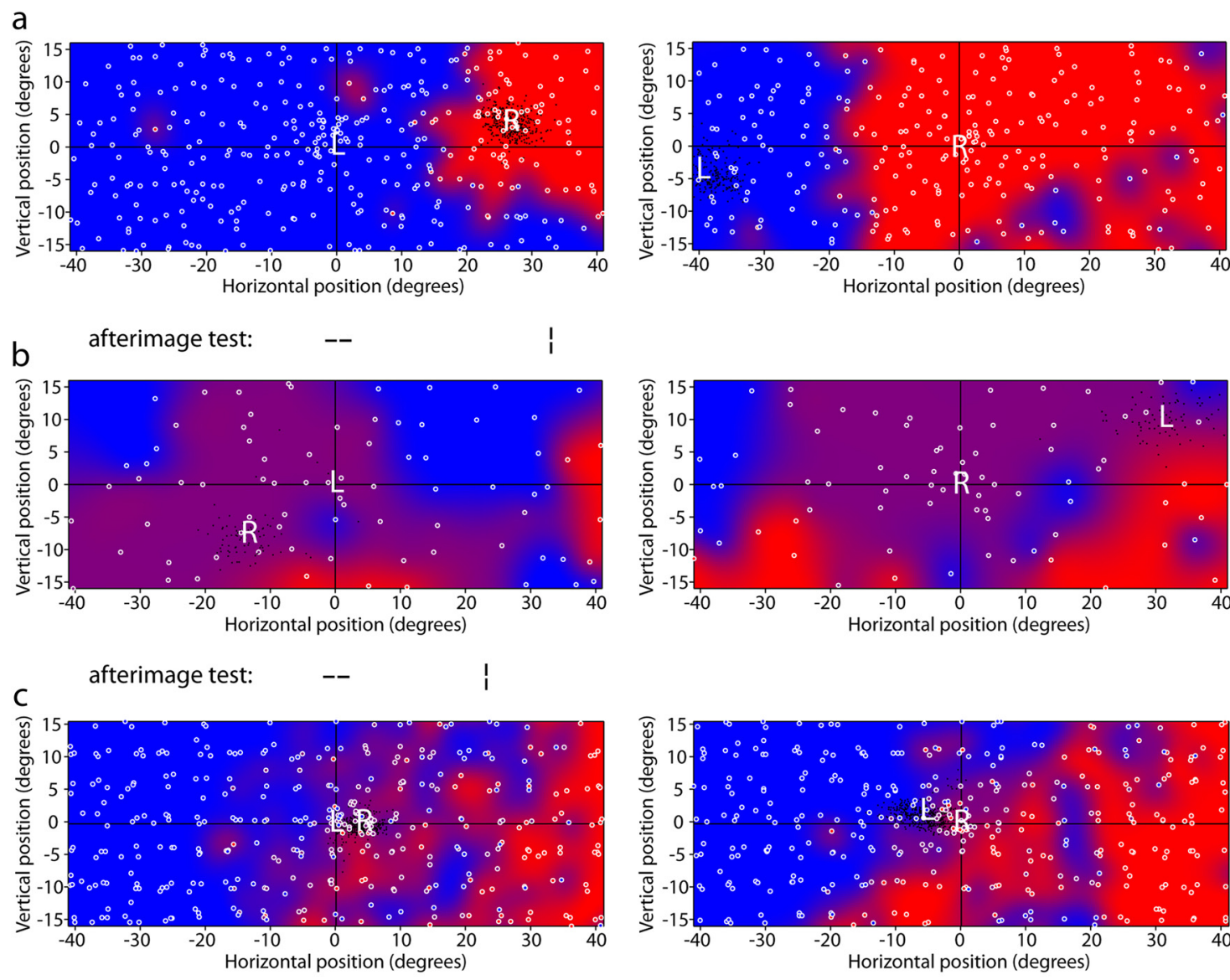

afterimage test: $\quad$-- |

Figure 8. Dichoptic visual field mapping in subject 2. $a$, Color-coded responses to a purple spot presented with either the left or right eye fixating at the origin. Testing was extended to $\pm 40^{\circ}$ because the exotropia was large, averaging nearly $30^{\circ}$. Afterimage test shows the horizontal position drawn by the patient of a slit flashed onto the left fovea (horizontal) and the right fovea (vertical). $\boldsymbol{b}$, Dichoptic visual field mapping after surgery. With either eye fixating at the origin, the other eye was crossed, signifying an esotropic deviation. To a purple spot, the subject responded "both" at most locations, indicating that she had diplopia. The afterimage test showed that the right fovea (vertical slit) was still perceived at $23^{\circ}$ to the right, although it now projected $15^{\circ}$ to the left of the left fovea (horizontal slit). c, Subject 2 after restoration of an exotropia, measuring $5^{\circ}$. The suppression scotomas appear similar to those mapped before the first operation (a), although responses are inconsistent centrally, accounting for the subject's report that diplopia had not resolved entirely. Afterimage test showed an anomalous retinal correspondence of $5^{\circ}$, close to the ocular deviation.

fields. The eye usually suppressed in physiological recordings should depend on where cells are sampled in the retinotopic map.

Striate cortex is the last point in the afferent visual system where inputs are segregated by eye, making it an obvious potential site for the neural control of interocular suppression. The inputs serving each eye project to layer $4 \mathrm{C}$, where they are organized into alternating bands called ocular dominance columns (Hubel and Wiesel, 1977). In normal primates, histochemistry for a mitochrondrial enzyme, cytochrome oxidase (CO), reveals no pattern in layer 4C (Horton and Hubel, 1981). In contrast, several distinct patterns of $\mathrm{CO}$ activity have been described in strabismic monkeys with alternating fixation (Tychsen and Burkhalter, 1997; Horton et al., 1999; Fenstemaker et al., 2001; Wong et al., 2005). These abnormal patterns correlate with the organization of suppression scotomas mapped in the exotropic subjects studied in this present report.

The first abnormal pattern consists of thin, pale strips running along the borders between ocular dominance columns, where binocular cells are concentrated (Horton and Hocking, 1998). This enzyme pattern occurs only in the portion of striate cortex where the central visual field is represented. Here, both retinas remain perceptually active as subjects alternate ocular fixation of visual targets (Fig. 7). Pale CO staining appears along the borders of ocular dominance columns because binocular function is lost, but monocular function remains relatively intact. The second abnormal CO pattern consists of dark columns alternating with pale columns. The pale columns match the ocular dominance columns of the ipsilateral eye (Horton et al., 1999). This pattern is encountered in striate cortex representing the peripheral visual fields, where the temporal retina of the ipsilateral eye is suppressed continuously (Fig. 7).

Functional magnetic resonance imaging (fMRI) has shown that suppression in strabismus results in attenuation of the blood oxygenation level-dependent signal in the foveal representation of striate cortex (Conner et al., 2007; Chen and Tarczy-Hornoch, 2011; Farivar et al., 2011). However, the strabismic subjects in these studies also had amblyopia in the deviated eye. It would be informative to examine fMRI signals in different regions of striate cortex in strabismic subjects without amblyopia, especially in the foveal representation during epochs of right eye versus left eye fixation.

A remarkable feature of the suppression scotomas that we mapped in each strabismic subject was that the fovea of the deviated eye was spared (Fig. 6). Afterimage testing showed that sub- 
jects avoided visual confusion by shifting the perceived location of images to offset globe rotation. The neural basis of this perceptual adaptation is unknown. In kittens raised with strabismus, the receptive fields of monocular cells recorded at any given site in the primary visual cortex remain faithful to their retinal location (Hubel and Wiesel, 1965). Consequently, anomalous retinal correspondence must arise at a higher level of the visual system (Cynader et al., 1984; Grant and Berman, 1991; Sireteanu and Best, 1992). In posterior parietal cortex, some neurons cancel eye displacements by encoding receptive field location in a headcentered reference frame (Andersen et al., 1985; Avillac et al., 2005). Neurons in the ventral intraparietal area can even shift their receptive fields partially or asymmetrically in response to horizontal versus vertical eye movements (Duhamel et al., 1997).

In subjects with strabismus the ocular deviation varies in magnitude, for several reasons. It changes slightly with shifts in gaze. It also changes with vergence effort. Finally, there is instability in the position of the nonfixating eye, represented by the cloud of foveal points in each visual field map (Fig. 6). The visual system is capable of rapidly adjusting the correspondence between the retinas to reflect these momentary changes in strabismus angle. In extreme cases, subjects with intermittent exotropia can switch from fusion with normal retinal correspondence to an exotropic state with anomalous retinal correspondence (Ramachandran et al., 1994). It is interesting to contemplate how such transformations occur. Information about eye movements that result in a change in strabismus angle may be used to update the correspondence between the retinas (Duhamel et al., 1992; Das, 2011). Proprioceptive feedback from the eye muscles could also be exploited (Wang et al., 2007).

Immediately after strabismus surgery, subjects misreach for visual targets seen with the operated eye (Bock and Kommerell, 1986). They adjust rapidly, presumably by integrating tactile and visual information to recalibrate retinal correspondence. Double vision and confusion are seldom reported. However, switching the eyes surgically from an exotropic position to an esotropic position usually results in protracted double vision (von Noorden and Campos, 2002) (Fig. 8b). Suppression scotomas do not shift quickly to prevent double vision after a horizontal reversal of foveal position, perhaps because such reversals do not occur naturally during eye movements in strabismic subjects.

As mentioned earlier, exotropic subjects have an expanded total field of vision. One fovea is also remapped to a location that is peripheral in the visual field, in a head- or body-centered reference frame. It is interesting to consider how strabismic subjects cope with both foveas being active perceptually, but aimed in different visual directions. In binocular rivalry, fMRI signals in V1 are modulated weakly by the visibility or invisibility of a target (Watanabe et al., 2011). A far stronger response is induced when attention is directed to a target. In strabismus, it is likely that subjects can pay attention to only one fovea at a time, although neither is suppressed. The center of gaze, and the subject's visual attention, remains associated with the fovea being used moment by moment to saccade to targets of interest.

\section{References}

Andersen RA, Essick GK, Siegel RM (1985) Encoding of spatial location by posterior parietal neurons. Science 230:456-458.

Anstis S, Cavanagh P (1983) A minimum motion technique for judging equiluminance. In: Colour vision, physiology and psychophysics (Mollon JD, Sharpe LT, eds), pp 155-166. London: Academic.

Avillac M, Denève S, Olivier E, Pouget A, Duhamel JR (2005) Reference frames for representing visual and tactile locations in parietal cortex. Nat Neurosci 8:941-949.
Bock O, Kommerell G (1986) Visual localization after strabismus surgery is compatible with the "outflow" theory. Vision Res 26:1825-1829.

Chen VJ, Tarczy-Hornoch K (2011) Functional magnetic resonance imaging of binocular interactions in visual cortex in strabismus. J Pediatr Ophthalmol Strabismus 48:366-374

Chiles JP, Delfiner P (1999) Geostatistics, modeling spatial uncertainty. New York: Wiley.

Conner IP, Odom JV, Schwartz TL, Mendola JD (2007) Retinotopic maps and foveal suppression in the visual cortex of amblyopic adults. J Physiol 583:159-173.

Cooper J, Feldman J (1979) Panoramic viewing, visual acuity of the deviating eye, and anomalous retinal correspondence in the intermittent exotrope of the divergence excess type. Am J Optom Pysiol Opt 56:422-429.

Cooper J, Record CD (1986) Suppression and retinal correspondence in intermittent exotropia. Br J Ophthalmol 70:673-676.

Cynader M, Gardner JC, Mustari M (1984) Effects of neonatally induced strabismus on binocular responses in cat area 18. Exp Brain Res 53:384-399.

Das VE (2011) Cells in the supraoculomotor area in monkeys with strabismus show activity related to the strabismus angle. Ann N Y Acad Sci 1233:85-90.

Donahue SP (2007) Clinical practice. Pediatric strabismus. N Engl J Med 356:1040-1047.

Duhamel JR, Colby CL, Goldberg ME (1992) The updating of the representation of visual space in parietal cortex by intended eye movements. Science 255:90-92.

Duhamel JR, Bremmer F, Ben Hamed S, GrafW (1997) Spatial invariance of visual receptive fields in parietal cortex neurons. Nature 389:845-848.

Farivar R, Thompson B, Mansouri B, Hess RF (2011) Interocular suppression in strabismic amblyopia results in an attenuated and delayed hemodynamic response function in early visual cortex. J Vis 11:pii:16.

Fenstemaker SB, Kiorpes L, Movshon JA (2001) Effects of experimental strabismus on the architecture of macaque monkey striate cortex. J Comp Neurol 438:300-317.

Fox R, Aslin RN, Shea SL, Dumais ST (1980) Stereopsis in human infants. Science 207:323-324.

Freeman RD, Tsumoto T (1983) An electrophysiological comparison of convergent and divergent strabismus in the cat: electrical and visual activation of single cortical cells. J Neurophysiol 49:238-253.

Friedman DS, Repka MX, Katz J, Giordano L, Ibironke J, Hawse P, Tielsch JM (2009) Prevalence of amblyopia and strabismus in white and African American children aged 6 through 71 months the Baltimore Pediatric Eye Disease Study. Ophthalmology 116:2128-2134.e1-2.

Grant S, Berman NE (1991) Mechanism of anomalous retinal correspondence: maintenance of binocularity with alteration of receptive-field position in the lateral suprasylvian (LS) visual area of strabismic cats. Vis Neurosci 7:259-281.

Herzau V (1980) Untersuchungen Über Das Binokulare Gesichtsfeld Schielender. Doc Ophthalmol 49:221-284.

Hillis JM, Banks MS (2001) Are corresponding points fixed? Vision Res 41:2457-2473.

Horton JC, Hocking DR (1998) Monocular core zones and binocular border strips in primate striate cortex revealed by the contrasting effects of enucleation, eyelid suture, and retinal laser lesions on cytochrome oxidase activity. J Neurosci 18:5433-5455.

Horton JC, Hubel DH (1981) Regular patchy distribution of cytochrome oxidase staining in primary visual cortex of macaque monkey. Nature 292:762-764.

Horton JC, Hocking DR, Adams DL (1999) Metabolic mapping of suppression scotomas in striate cortex of macaques with experimental strabismus. J Neurosci 19:7111-7129.

Hubel DH, Wiesel TN (1965) Binocular interaction in striate cortex of kittens reared with artificial squint. J Neurophysiol 28:1041-1059.

Hubel DH, Wiesel TN (1977) The Ferrier Lecture: functional architecture of macaque monkey visual cortex. Proc R Soc Lond B Biol Sci 198:1-59.

Jampolsky A (1955) Characteristics of suppression in strabismus. AMA Arch Ophthalmol 54:683-696.

Johnson CA, Keltner JL (1980) Automated suprathreshold static perimetry. Am J Ophthalmol 89:731-741.

Joosse MV, Simonsz HJ, de Jong PT (2000) The visual field in strabismus: a historical review of studies on amblyopia and suppression. Strabismus 8:135-149. 
Joosse MV, Simonsz HJ, van Minderhout EM, Mulder PG, de Jong PT (1999) Quantitative visual fields under binocular viewing conditions in primary and consecutive divergent strabismus. Graefes Arch Clin Exp Ophthalmol 237:535-545.

Mehdorn E (1989) Suppression scotomas in primary microstrabismus-a perimetric artefact. Doc Ophthalmol 71:1-18.

Melek N, Shokida F, Dominguez D, Zabalo S (1992) Intermittent exotropia: a study of suppression in the binocular visual field in 21 cases. Binocul Vis Strabismus Q 7:25-30.

Mullen KT, Kingdom FA (2002) Differential distributions of red-green and blue-yellow cone opponency across the visual field. Vis Neurosci 19:109-118.

Packer O, Diller LC, Verweij J, Lee BB, Pokorny J, Williams DR, Dacey DM, Brainard DH (2001) Characterization and use of a digital light projector for vision research. Vision Res 41:427-439.

Pathai S, Cumberland PM, Rahi JS (2010) Prevalence of and early-life influences on childhood strabismus: findings from the Millennium Cohort Study. Arch Pediatr Adolesc Med 164:250-257.

Pratt-Johnson J, Wee HS (1969) Suppression associated with exotropia. Can J Ophthalmol 4:136-144.

Ramachandran VS, Cobb S, Levi L (1994) The neural locus of binocular rivalry and monocular diplopia in intermittent exotropes. Neuroreport 5:1141-1144.

Sengpiel F, Freeman TC, Blakemore C (1995) Interocular suppression in cat striate cortex is not orientation selective. Neuroreport 6:2235-2239.

Sengpiel F, Jirmann KU, Vorobyov V, Eysel UT (2006) Strabismic suppression is mediated by inhibitory interactions in the primary visual cortex. Cereb Cortex 16:1750-1758.

Serrano-Pedraza I, Manjunath V, Osunkunle O, Clarke MP, Read JC (2011) Visual suppression in intermittent exotropia during binocular alignment. Invest Ophthalmol Vis Sci 52:2352-2364.

Shadlen M, Carney T (1986) Mechanisms of human motion perception revealed by a new cyclopean illusion. Science 232:95-97.
Sireteanu R (1982) Binocular vision in strabismic humans with alternating fixation. Vision Res 22:889-896.

Sireteanu R, Best J (1992) Squint-induced modification of visual receptive fields in the lateral suprasylvian cortex of the cat: binocular interaction, vertical effect and anomalous correspondence. Eur J Neurosci 4:235-242.

Travers TA (1938) Suppression of vision in squint and its association with retinal correspondence and amblyopia. Br J Ophthalmol 22:577-604.

Tychsen L, Burkhalter A (1997) Nasotemporal asymmetries in V1: ocular dominance columns of infant, adult, and strabismic macaque monkeys. J Comp Neurol 388:32-46.

Tychsen L, Wong AM, Burkhalter A (2004) Paucity of horizontal connections for binocular vision in V1 of naturally strabismic macaques: cytochrome oxidase compartment specificity. J Comp Neurol 474:261-275.

von Graefe A (1854) Über das Doppelsehen nach Schieloperationen und Incongruenz der Netzhaute. Arch f Ophthalmol 1:82-120.

von Noorden GK, Campos EC (2002) Binocular vision and ocular motility: theory and management of strabismus, 6th Edition. St. Louis, Mo.: Mosby.

Wang X, Zhang M, Cohen IS, Goldberg ME (2007) The proprioceptive representation of eye position in monkey primary somatosensory cortex. Nat Neurosci 10:640-646.

Watanabe M, Cheng K, Murayama Y, Ueno K, Asamizuya T, Tanaka K, Logothetis N (2011) Attention but not awareness modulates the BOLD signal in the human V1 during binocular suppression. Science 334:829-831.

Wong AM, Burkhalter A, Tychsen L (2005) Suppression of metabolic activity caused by infantile strabismus and strabismic amblyopia in striate visual cortex of macaque monkeys. J AAPOS 9:37-47.

Zhang B, Bi H, Sakai E, Maruko I, Zheng J, Smith EL 3rd, Chino YM (2005) Rapid plasticity of binocular connections in developing monkey visual cortex (V1). Proc Natl Acad Sci U S A 102:9026-9031. 